\title{
FMH-Zentralbeiträge 2007
}

Die ausserordentliche Ärztekammer vom 14./15. Dezember 2006 hat - nicht etwa auf Antrag des Zentralvorstandes oder des Präsidenten, sondern aufgrund eines spontanen Antrags aus den eigenen Reihen - folgende Beschlüsse gefasst, die sich auf den Zentralbeitrag 2007 auswirken:

1. Erhöhung des FMH-Grundbeitrags um Fr. 100.- (abgestuft nach Mitgliederkategorie), einmalig für das Jahr 2007 zur Tilgung des Budgetdefizits.

2. Sonderkredit für die Schaffung einer Health Professional Card HPC von Fr. 25.- (abgestuft nach Mitgliederkategorie)

Die Zentralbeiträge 2007 setzen sich neu* wie folgt zusammen:

\begin{tabular}{|c|c|c|c|c|c|c|}
\hline $\begin{array}{l}\text { Mitglieder- } \\
\text { kategorie }\end{array}$ & FMH-Grundbeitrag neu* & Sonderbeitrag HIN & $\begin{array}{l}\text { Sonderbeitrag } \\
\text { Praxisassistenz }\end{array}$ & $\begin{array}{l}\text { Sonderbeitrag } \\
\text { Newlndex }\end{array}$ & Sonderkredit HPC* & Total \\
\hline 1 und 2 & 630.- (530.-+100.-) & 35.- & 25.- & 45.- - & 25.- & 760.- \\
\hline 3 & 315.- (265.-+50.-) & 35.- & 25.- & 0.- & 12.- & 387.- \\
\hline 4 & $315 .-(265 .-+50 .-)$ & 0.- & 25.- & $0 .-$ & 12.- & 352.- \\
\hline 5 und 6 & 157.- (132.-+25.-) & $0 .-$ & 0.- & $0 .-$ & 6.- & 163.- \\
\hline
\end{tabular}

*Diese Erhöhungen werden vorbehältlich der 60tägigen Einsprachefrist ab Publikation des Protokolls der ausserordentlichen Ärztekammer (FMH-Statuten Art. 24, Abs. 2) wirksam. 